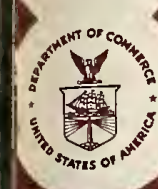

\title{
Description of the
}

Magnetic Tape Version of

\section{the Bulletin of Thermodynamics}

and Thermochemistry, No. 14 (1971)

U.S. JEPARTMENT OF COMMERCE

National Bureau of Standards 


\section{NATIONAL BUREAU OF STANDARDS}

The National Bureau of Standards ${ }^{1}$ was established by an act of Congress March 3, 1901. The Bureau's overall goal is to strengthen and advance the Nation's science and technology and facilitate their effective application for public benefit. To this end, the Bureau conducts research and provides: (1) a basis for the Nation's physical measurement system, (2) scientific and technological services for industry and government, (3) a technical basis for equity in trade, and (4) technical services to promote public safety. The Bureau consists of the Institute for Basic Standards, the Institute for Materials Research, the Institute for Applied Technology, the Center for Computer Sciences and Technology, and the Office for Information Programs.

THE INSTITUTE FOR BASIC STANDARDS provides the central basis within the United States of a complete and consistent system of physical measurement; coordinates that system with measurement systems of other nations; and furnishes essential services leading to accurate and uniform physical measurements throughout the Nation's scientific community, industry, and commerce. The Institute consists of a Center for Radiation Research, an Office of Measurement Services and the following divisions:

Applied Mathematics - Electricity - Mechanics - Heat - Optical Physics Linac Radiation ${ }^{2}$ - Nuclear Radiation ${ }^{2}$ - Applied Radiation ${ }^{2}$ - Quantum Electronics : - Electromagnetics ${ }^{3}$ - Time and Frequency ${ }^{3}$ - Laboratory Astrophysics : - Cryogenics ${ }^{3}$.

THE INSTITUTE FOR MATERIALS RESEARCH conducts materials research leading to improved methods of measurement, standards, and data on the properties of well-characterized materials needed by industry, commerce, educational institutions, and Government; provides advisory and research services to other Government agencies; and develops, produces, and distributes standard reference materials. The Institute consists of the Office of Standard Reference Materials and the following divisions:

Analytical Chemistry-Polymers-Metallurgy-Inorganic Materials-Reactor Radiation-Physical Chemistry.

THE INSTITUTE FOR APPLIED TECHNOLOGY provides technical services to promote the use of available technology and to facilitate technological innovation in industry and Government; cooperates with public and private organizations leading to the development of technological standards (including mandatory safety standards), codes and methods of test; and provides technical advice and services to Government agencies upon request. The Institute also monitors NBS engineering standards activities and provides liaison between NBS and national and international engineering standards bodies. The Institute consists of a Center for Building Technology and the following divisions and offices:

Engineering and Product Standards-Weights and Measures-Invention and Innovation-Product Evaluation Technology-Electronic Technology-Technical Analysis-Measurement Engineering-Building Standards and Code Services ${ }^{4}$ - Housing Technology ${ }^{4}$-Federal Building Technology ${ }^{4}$-Structures, Materials and Life Safety ${ }^{4}$-Building Environment ${ }^{4}$-Technical Evaluation and Application ${ }^{*}$-Fire Technology.

THE INSTITUTE FOR COMPUTER SCIENCES AND TECHNOLOGY conducts research and provides technical services designed to aid Government agencies in improving cost effectiveness in the conduct of their programs through the selection, acquisition, and effective utilization of automatic data processing equipment; and serves as the principal focus within the executive branch for the development of Federal standards for automatic data processing equipment, techniques, and computer languages. The Center consists of the following offices and divisions:

Information Processing Standards-Computer Information-Computer Services -Systems Development-Information Processing Technology.

THE OFFICE FOR NFORMATION PROGRAMS promotes optimum dissemination and accessibility of scientific information generated within NBS and other agencies of the Federal Government; promotes the development of the National Standard Reference Data System and a system of information analysis centers dealing with the broader aspects of the National Measurement System; provides appropriate services to ensure that the NBS staff has optimum accessibility to the scientific information of the world, and directs the public information activities of the Bureau. The Office consists of the following organizational units:

Office of Standard Reference Data-Office of Technical Information and Publications-Library-Office of International Relations.

\footnotetext{
1 Headquarters and Laboratorles at Galthersburg, Maryland, unless otherwlse noted; malling address Washington, D.C. 20234

Part of the Center for Radlation Research.

3 Located at Boulder, Colorado 80302.

- Part of the Center for Bullding Technolog.
} 


\section{Description of the Magnetic Tape Version}

of the Bulletin of Thermodynamics and Thermochemistry, No. 14 (1971)

Robert McClenon

Office of Standard Reference Data

National Bureau of Standards

Washington, D.C. 20234

William H. Evans and David Garvin

Physical Chemistry Division

Institute for Materials Research

National Bureau of Standards

Washington, D.C. 20234

and

Blanton C. Duncan

Computer Services Division

Institute for Computer Sciences and Technology

National Bureau of Standards

Washington, D.C. 20234

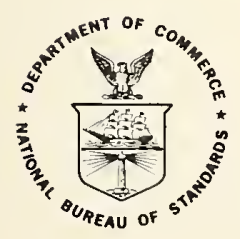

U.S. DEPARTMENT OF COMMERCE, Frederick B. Dent, Secrefary

NATIONAL BUREAU OF STANDARDS, Richard W. Roberts, Direcfor

Issued March 1973 
National Bureau of Standards Technical Note 760

Nat. Bur. Stand. (U.S.), Tech. Note 760, 51 pages (Mar. 1973) CODEN: NBTNAE 
1. Introduction 1

2. General Summary of the Work 3

3. Description of an Entry 5

4. Sequence of Files and Structure 10

5. Technical Description of the Record 12

Appendices

A. Codes for Properties Used on B.I. and T. Iapes 18

B. Glossary of Symols for the Substance-Property Index

C. Codes for States Used on B.T. and T. Tapes

D. Organic Compound liain and Group Classes

E. Finding Jumber Sequence for the Elements Used on B.T. and $\mathrm{I}$. Tapes

F. Flags (Used on B.T. and T. Tapes)

G. Display of Data Recording ("Dump") 



$$
\begin{aligned}
& \text { Description of the } \\
& \text { Magnetic Tape Version of the } \\
& \text { Bulletin of Thermodynamics and } \\
& \text { Thermochemistry, No. } 14 \text { (1971) }
\end{aligned}
$$

Robert C. McClenon, William H. Evans

David Carvin and Blanton C. Duncan

\section{Abstract}

The substance-property index and bibliography sections of the Bulletin of Thermodynamics and Thermochemistry, No. 14 (May 1971) have been converted to a magnetic tape version designed for computerized searching written in an extended form of the American National Standard Code for Information Interchange (X 3.4-1968). In this version each substance-property entry has been supplemented by a searching key. This report describes the magnetic tape version.

Key words: Bibliography; chemical thermodynamics; extended character codes; information retrieval; magnetic tape.

\section{Introduction}

The Bulletin of Thermodynamics and Thermochemistry (B. T. and T.) is an annual publication prepared under the auspices of the Commission of Thermodynamics and Thermochemistry of the Division of Physical Chemistry of the International Union of Pure and Applied Chemistry. It is edited by Professor Edgar F. Westrum, Jr., University of Michigan, Ann Arbor, Michigan. 
The Bulletin contains (a) abstracts of work in progress during a calendar year, (b) a substance-property index to these abstracts and to papers published during the same period, and, (c) a bibliography to which the index is keyed.

The final stages of preparing the substance-property index and the bibliography are carried out at the National Bureau of Standards by the Chemical Thermodynamics Data Group, Physical Chemistry Division, Institute for Materials Research. At this stage the entire contents of the index and bibliography are stored on magnetic tape and are manipulated using the General Purpose Scientific Document Code System.

The tapes for Bulletin of Thermodynamics and Thermochemistry, No. 14 (May 1971), covering 1970, have been used to prepare a machine-readable record that can be used in computerized information retrieval systems. This report explains the structure of the records, the chemical symbolism used and the technical characteristics of the machine record. It should be a sufficient starting point for the transcription of the record at a computer center and use of the material by chemists. 


\section{General Summary of the Work}

Chemistry requires a complex symbolism, even for a compound-oriented index. Figure 1, a page from the Bulletin shows this. There are upper and lower case letters, subscripts and superscripts and occasional Greek letters. Underscoring is used to indicate type-face changes.

All of these features are present on the machine-readable record. The index sections of the record are line-by-line copies of each column in the index supplemented by a searching key that summarizes the entry in a rigidly prescribed manner (See Section 3). The bibliography sections of the record are line-by-line copies of the bibliography in the Bulletin.

The substance-property index in the Bulletin is in three parts: organic substances, organic mixtures and inorganic substances. The machine record also is in several parts corresponding to the division in the Bulletin. This overall structure is described in Section 4.

The machine record is written in the American National Standard Code for Information Interchange (ASCII-1968) which is a variant of the International Standardization Organization Code (ISO/IS 646). In order to obtain special features (subscripts, Greek etc.) the ASCII-1968 code has been supplemented with an additional set of characters and several specially defined escape code sequences. The technical details of the machine record are described in Section 5.

The potential user of the tape will face two major tasks which are not discussed further in this report. First, he must obtain a program that will read and transcribe the ASCII records into a form usable on his computer system. Second, he must develop or obtain a program that can search the records. 
The first task is one which should preferably be done by the computer

service center rather than by the individual user, since the result will be a utility program applicable to any ISO or ASCII tape. The second task may be either simple or complex. This depends upon whether a simple character by character comparison of chemical formulae is to be used or whether the detailed information in the searching key is to be used to make the search more efficient. 
Each of the index files in the Bulletin of Thermodynamics and Thermochemistry is divided into basic logical groups of information known as entries. Each entry contains a reference number, correlating it to an entry in the corresponding bibliographic file, and additional information intended to permit mechanized searching of the Bulletin. The entry consists of:

(a) Two lines of coded information followed by one line per compound in the entry.

(b) The text as printed in the Bulletin. This is of ten one line, but may be several lines long.

A typical entry is shown in figure 2.

\subsection{First Line:}

The first character in the first line of an entry is an ASCII Group Separator. This denotes the start of an entry. Columns 2 through 6 contain a sequence number which is assigned to the entry by the program generating the tape. The entry appearing first on the tape is assigned the number 1; the second number is assigned the number 2; the thousandth entry is assigned the number 1000, and so on. This number (like every number in the first two lines of an entry) is right justified in its field: the units digit is in column 6. In the example shown in figure 2, the sequence number is 141 .

Columns 8 and 9 (or, if the number is one digit, column 9 only) contain the number of lines in the entry. In the example shown, there are five lines, therefore this number is 5 . 
Column 11 contains the number of substances for which chemical formulas are given, one per line. The maximum number of substances indexed in this way is 3. If more than three substances are present in an alloy or a mixture, only the first three are indexed, and the entry is permuted "end-around" so that all substances are indexed. In the example shown, two substances (water and hydrogen chloride) are indexed.

Column 13 contains the number of property codes for which the substance described has been indexed. The maximum value of this number is 3. The property codes are given in columns 14 and 15; columns 16 and 17; and columns 18 and 19. The document described by the entry in figure 2 discusses two properties, having the codes 17 and 28. The zero in column 19 occurs because there is no third property. If more than three property codes are present in the entry, only the three lowest are given. Appendices $A$ and $B$ give the meanings of the property codes.

Note that there are two sets of property codes. One is for compounds for which a formula is given. The other is for miscellaneous subjects. The numerical values in the two sets overlap.

Columns 21 and 22 contain a numerical state code. Meanings of the state codes are given in Appendix $C$. The 45 in figure 2 indicates a liquid-gas transition.

Columns 24 through 27 give the class code for an organic compound. Columns 28 through 30 give the subclass code. These are explained in Appendix D. In figure 2 they are zeroes because the entry is from the inorganic file. Values of 1023 for the class code and 255 for the subclass may also occur for inorganic entries. 
Columns 32 through 34 contain a "finding number" for the substances described on the first substance line. The finding number is based on the standard order of arrangement of the elements (see NBS Technical Note 270). It indicates the element in the first substance that occurs last in the standard order. Appendix E lists the element to which each finding number corresponds. For example, in figure 2, the substance listed first is water. Since hydrogen follows oxygen in the standard order, the finding number is that of hydrogen, which is 2. Certain entries may have anomalously large finding numbers, such as 117. Such a number indicates that the item was filed in the "General and Miscellaneous" section of the index, e.g. starting at p. 252 of the Bulletin, number 14. The subheadings in this section are the property codes for miscellaneous items.

Columns 41 through 48 contain the reference number. This specifies the bibliographic entry to which this index entry refers. In the example shown, the reference number is 5157-70. Note that this number appears twice in each index entry.

This line is always present. It is 47 or 48 characters long, not including control codes.

\subsection{Second Line:}

The second Iine contains numerical "flags" alerting a searcher to special characteristics of an indexed substance. Column 1 contains the number of flags for the first substance, column 2, for the second substance, column 3, for the third substance. There may be from 0 to 5 flags for a substance. Each flag consists of two digits. Since there may be up to 15 flags, 30 columns are reserved for the flags ( 10 columns 
for each substance). The flags for the first substance are in columns 4 through 13. Those for the second substance are in columns 14 through 23. Those for the third substance are in columns 24 through 33 . The information in columns 1 through 3 indicates that there is a single flag for the first substance. This flag, a 3, is found in column 5 (actually columns 4 and 5). Appendix F makes it clear that this flag identifies the first compound, water, as a component of a mixture, to be followed by (at least) one more component. The flags 2, indicating a hydrate, 11, indicating positive charge, and 12 , indicating negative charge, are each followed by a number which is not actually another flag but a count. For a hydrate it is the number of molecules of water of hydration. For an ion it represents the number of charges.

This line is always present; it may be 3 to 33 characters long, not including control codes.

\subsection{Formula Lines:}

An empirical formula for each substance is part of each entry. Each formula appears on a separate line. The example given in Figure 2 illustrates two significant features of the formula. First, the elements in a formula are arranged in reverse standard order of arrangement. Thus hydrogen chloride is written $\mathrm{Cl}_{1} \mathrm{H}_{1}$. Second, a subscript " 1 " follows the symbol for an element of which the compound contains one atom. This permits the formula to be converted into a 6-bit code (e.g., BCD) in which no distinction is made between upper and lower case, without ambiguity. The formula may be followed by a slash, which indicates that it is one of the components of an alloy or a system, in which case the next component is on the next line. 


\subsection{Text:}

Following the substance lines, the text of the index as printed in the Bulletin appears on the tape. One may note the correspondence between the substance lines and the formula in the text; between the state abbreviation following the formula in the text, and the state code in columns 21 and 22 of the first line; and between the property symbols beginning in column 31 of the first line of text, and the property codes in columns 14 through 19. 


\section{Sequence of Files and Structure}

The Bulletin tape consists of six files. The first record on the tape is a standard volume header label as described in ANSI X3.27-1969. It is followed immediately by the file header labels for the first file. Each file is preceded by two standard file header labels (followed by a tape mark). The file itself is followed by a tape mark; and the file and its tape mark are followed by a standard end-of-file label and a tape mark. Two tape marks follow the final end-of-file label. This structure is shown in figure 3.

The first file contains the substance-property index to the inorganic section of the Bulletin. Its format is described in Chapter 3. The second file contains the index for organic compounds. The third file contains the index for organic mixtures. The maximum length of a line in an index file is 48 characters.

The fourth through sixth files contain the bibliographic portion of the Bulletin for the inorganic, organic compound, and organic mixture sections respectively. * These files are images of the bibliographic parts of the printed Bulletin. The first line of a bibliographic entry begins in column 1 with a digit. Each continuation line of an entry begins in column 4. The maximum length of a line is 110 characters. Note that group separators do not precede entries in the bibliography.

The following table gives the number of 1008-character blocks and of lines in each file. (A "line" consists of a line feed followed by at

* Note that the inorganic reference numbers start 3001 , organic substances at 0001 and organic mixtures at 1001 . 
least one graphic character and possibly other characters, followed by a carriage return).

$\begin{array}{ccc}\text { File } & \text { \# Blocks } & \text { \# Lines } \\ 1 & 1526 & 40470 \\ 2 & 347 & 8917 \\ 3 & 980 & 26301 \\ 4 & 493 & 5224 \\ 5 & 101 & 1097 \\ 6 & 249 & 2441\end{array}$


5.1 The tape is a standard $0.5 \mathrm{in.}(1.27 \mathrm{~cm})$ wide magnetic tape.

5.2 The recording is in 9 tracks at a density of 800 characters per inch ( 315 per $\mathrm{cm}$ ). There are 1008 characters per physical record. Each record is followed by an $0.6 \mathrm{in}$. $(1.52 \mathrm{~cm})$ record gap.

5.3 The information is recorded using the American National Standard Code for Information Interchange, ASCII-1968, Document X 3.4-1968, with certain extensions described in section 5.5, below. This is a 7 bit code. The eighth bit available for recording information on a 9 track tape is always zero. That means that the information itself has been recorded without the parity bit usually included on paper tape records.

5.4 Standards. The recording has been prepared in conformance with the pertinent standards. The American National Standard Code is a recognized variant of the International Standard Code for Information Processing Interchange, ISO/IS 646. Recipients not familiar with the developing body of formal standards for information interchange will find it useful to study some of the basic standards. Within the U.S.A. the essential set of standards (one still in draft) is:

(1) X 3.4-1968, American National Standard Code for Information Interchange (FIPS Publication 1)

(2) X 3.22-1967, American National Standard Recorded Magnetic Tape for Information Interchange ( 800 CPI,NP.ZI) (FIPS Publication 3) (3) X 3.26-1970, American National Standard Hollerith Punched Card Code (FIPS Publication 14)

(4) X 3.27-1969, American National Standard Magnetic Tape Labels for Information Interchange

(5) X3L2/1199, American National Standard Code Extension Techniques for Use with the 7-Bit Coded Character Set of ASCII. 
All these standards can be considered as derivatives of corresponding ISO standards. They may be obtained from the American National Standards Institute. Recipients in other countries can expect to be able to obtain copies of their own corresponding national standards from their national standards agencies.

5.5 Special features on this tape. The tape is designated as being a "GPDW03" tape (General Purpose Document Writer-03). This means that we have (a) defined the meaning of six Escape sequences and (b) defined an alternative set of graphics to supplement the basic ASCII set. (a) The escape sequences and their uses here are:

Sequence Meaning at a Teletypewriter

Use in GPDWO3

ESC 3 Shift to Red Ribbon

(alternative graphic set)

ESC $\underline{4}$

Shift to Black Ribbon (basic graphic set)

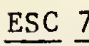

Reverse Line Feed

(up one line)

ESC $\underline{8}$

Keverse One-half Line Feed

(up $1 / 2$ line)

ESC 9

Forward One-half Line Feed

(down $1 / 2$ line)

$\underline{\text { ESC } \%} \underline{3}$

Standard Designator for GPDWO3 as a Code Requiring Special Interpretation

The first five Escape sequences occur in the body of the text. ESC 3 and ESC 4 signal changes of graphic character sets. "Shift Out" (SO) is not used on this tape to signal changes of graphic sets because it has been assigned a specific meaning in some national standards. On the other hand, Shift In (SI) does occur at the beginning of each page of text. 
ESC 7, ESC 8 and ESC 9 are used to signal the motion of a printing device to and from positions needed for superscripts and subscripts.

The final sequence, ESC \% 3 appears at the start of each physical record. It warns that the GPDWO3 conventions are being used.

(b) The graphic character sets and their numerical codes are defined in figure 4 .

5.6 Examples of recordings. A computer programmer who must arrange to read a magnetic tape that has been prepared outside his installation needs a printed example of the record on the tape. This will be used to check the performance of the hardware tape-reading facility when reading the foreign tape. Appendix $G$ contains such a printed record, a "dump" of part of this tape. It is a representation in limited symbolism, character by character, of several lines of text. The actual numerical codes can be obtained by interpreting this dump using figure 4 .

It may also help the recipient who plans to transcribe this tape to be aware of the following conventions:

(1) The text is broken into lines. A carriage return (CR), line feed (LF) sequence signals the end of the line. This sequence has several delete (DEL) codes in it.

(2) The only other use of carriage return is in a sequence at the start of a page. A page start is indicated by form feed (FF) and carriage return together with several (DEL) codes. 
(3) Delete codes (DEL) have been inserted whenever it is desirable to provide for a time delay during the mechanical motion of a printing device.

(4) Lines of text may start in one physical record and end in the next. Even in this case, the sequence ESC \% 3 is placed at the start of the second physical record.

(5) Line feed (LF) controls may occur within the recording for a line of text. This can happen when movement from a superscript level to a subscript level is required.

(6) Lines are always separated by at least one blank half-line interval.

(7) Backspace (BSP) is used, often to achieve overstriking of characters. Backspace does not carry the meaning "backspace and delete the previous character."

(8) Shift In (SI) occurs regularly in the pagination sequence (see 2 , above). This is done in order to reestablish periodically a standard default condition in case of error.

5.7. Discussion. Although the statements above are definitive, they do not make it clear that we have exploited almost all of the features of the ASCII (or ISO) code system in this recording. This subsection attempts to explain the matter.

The record on the tape is a teletypewriter driver record, that is, a sequence of control and graphic codes that could cause a typewriter-like device that responds to ASCII to produce a clean copy, line by line, of the information. The features that this idealized teletypewriter (the target device) must have are described below. 
(1) The target device is a character sequential page printer, i.e. a "typewriter-like reference transducer." This assumption reflects an attempt to invoke a broadly acceptable lowest common denominator for data interchange and dissemination.

(2) The target printer can print only the 94 graphic characters of ASCII, e.g. in the columns labeled "Std", figure 4.

(3) The target printer provides two color printing, e.g. black and red, subject to being invoked under code control. Symbols printed in red are to be interpreted as symbols from the alternative set of 94 graphic characters.

(4) The target printer provides forward and reverse half line feed under code control. By this means all symbols are subject to being placed in the positions of superscripts or overscores and subscripts or underscores.

(5) The target printer provides backspace under code control so that the effective graphic repertory includes composite sysmbols formed by overstriking.

(6) The target printer provides separate "carriage return" and "line feed" functions, i.e. carriage return implies no vertical motion. In addition, the device provides a reverse line feed function under code control. It may be noted that two-half line feed intervals are taken to equal one line feed interval, exactly.

(7) The target printer provides a "form feed" or "page eject" function under code control. 
Teletypewriters with these capabilities are available as offthe-shelf items. One of them was used to keyboard the copy from which figure 4 was printed.

Typewriter-like devices with more limited characteristics can still produce interpretable, but slightly less readable records from GPDWO3 tapes. In addition, such a tape can be "dumped" on a line printer. Such a dump is shown in Appendix G. 
Appendix A

Codes for Properties used on BT of $\mathrm{T}$ tapes

\begin{tabular}{|c|c|c|c|c|}
\hline Property Class & Tape Code & Property Class & Tape & Cod \\
\hline none (blank) & 0 & 8 & & 30 \\
\hline 0 & 1 & $8 c$ & & 31 \\
\hline 1 & 3 & $8 \mathrm{~h}$ & & 33 \\
\hline 2 & 4 & $8 \mathrm{~s}$ & & 35 \\
\hline $2 \mathrm{p}$ & 7 & & & \\
\hline $2 q$ & 9 & 9 & & 37 \\
\hline & & $9 c$ & & 41 \\
\hline 3 & 10 & $9 r$ & & 39 \\
\hline $3 d$ & 11 & & & \\
\hline $3 e$ & 13 & & & \\
\hline $3 \mathrm{k}$ & 15 & & & \\
\hline $3 \mathrm{~s}$ & 17 & & & \\
\hline 4 & 19 & & & \\
\hline $4 e$ & 21 & & & \\
\hline $4 \mathrm{f}$ & $19(=4)$ & , & & \\
\hline 5 & 23 & & & \\
\hline 6 & 25 & & & \\
\hline 7 & 26 & & & \\
\hline $7 c$ & 27 & & & \\
\hline $7 g$ & 28 & & & \\
\hline $7 t$ & 29 & & & \\
\hline
\end{tabular}


TABLE I. GLOSSARY OF SYMBOLS FOR THE SUBSTANCE-PROPERTY INDEX

Property Symbo1

Category Subgroup

0

1

2

$2 \mathrm{p}$

$2 q$

3

$3 d$

$3 e$

$3 \mathrm{k}$

$3 \mathrm{~s}$

4

$4 e$

$4 f$

5

6

7

$7 c$

$7 \mathrm{~g}$

$7 \mathrm{t}$

8

$8 c$

$8 \mathrm{~h}$

$8 \mathrm{~s}$

9

$9 c$

$9 r$
Description of Properties

Calorimetric heats of reaction

Calorimetric heats of solution, mixing and dilution

Phase change equilibria

Physical properties for pure substances, melting point, transition temperature, boiling point, vapor pressure, and derived data

Calorimetric heats and entropies of transition, fusion and vaporization

Equilibrium data and derived properties

Dissociation pressures

Electrochemica 1 data

Equilibrium constants

Solubilities, vapor pressures of solutions, activities, and related data

Thermodynamic functions from molecular properties

Molecular and spectroscopic data

Thermodynamic functions of gases

Physical properties of single phases. Density, refractive index, and viscosity

Spectroscopic studies of molecular bonding

P-V-T data

Effect of pressure on condensed phases: compressibility, Mollier diagrams

Effect of pressure on gases, PVT data, critical state, Joule-Thomson coefficient

Tables and charts

Calorimetric entha1py:

Low temperature heat capacity and entha1py

High temperature heat content (enthalpy) and capacity

Third Law entropy

Reviews and compilations:

Correlation reviews

Reviews and compilations

Papers on apparatus, theoretical topics, etc., are contained in the section headed Miscellaneous (below)

Physical States: (c)rystal, solid

(amorp)hous

(1iq) uid

(g) as

(gls) glass (aq) ueous

(nonaq)ueous, includes fused salts

(ads)orbed

(sol)ution 


\section{Subject}

1. Properties of real materials

2. Calorimetric apparatus - Reaction calorimetry

3. Calorimetric apparatus - Heat capacity and heat content

4. Solutions and solution theory

5. Properties of real fluids

6. Temperature measurement and scales

7. Pressure measurement and scales

8. Correlations, bond energies, and estimates

9. Thermodynamic theory 
Appendix C

Codes for States used on BT and T Tapes

c

amorph $\quad 12 \quad 22$

glass $\quad 13 \quad 23 \quad 33$

liquid $\quad 14 \quad 24 \quad 34 \quad 44$

gas $\quad \begin{array}{lllll}15 & 25 & 35 & 45 & 55\end{array}$

$\begin{array}{lllllll}\text { aq } & 16 & 26 & 36 & 46 & 56 & 66\end{array}$

$\begin{array}{llllllll}\text { soln } & 17 & 27 & 37 & 47 & 57 & 67 & 77\end{array}$

$\begin{array}{lllllllll}\text { nonaq } & 18 & 28 & 38 & 48 & 58 & 68 & 78 & 88\end{array}$

$\begin{array}{llllllllll}\text { adsorbed } & 19 & 29 & 39 & 49 & 59 & 69 & 79 & 89 & 99\end{array}$

Examples: $12=\mathrm{c} /$ amorph or amorph/c [process]

$$
\begin{aligned}
& 22=\text { amorph (single state) or amorph/amorph } \\
& 00=\text { no state given }
\end{aligned}
$$


National Bureau of Standards

Chemica1 Thermodynamics Data Group

Tentative List (1972) of

\section{Organic Compound Main Classes}

\begin{tabular}{|c|c|}
\hline 01 & Trganic (general, used with \\
\hline 02 & Aliphatic \\
\hline 03 & Alicyclic \\
\hline 04 & Aromatic \\
\hline 05 & Aliphatic-Alicyclic \\
\hline 06 & Aliphatic-Aromatic \\
\hline 07 & Alicyclic-Aromatic \\
\hline 08 & Aliphatic-Alicyclic-Aromatic \\
\hline 09 & Spiro \\
\hline 10 & Terpene \\
\hline 11 & Heterocyclic-Oxygen Compounds, Monocyclic Ring, $<5$ atoms \\
\hline 12 & Heterocyclic-Oxygen Compounds, Monocyclic Ring, \\
\hline 13 & Heterocyclic-Oxygen Compounds, Monocyclic Ring, \\
\hline 14 & Heterocyclic-Oxygen Compounds, Monocyclic Ring, $>6$ atoms \\
\hline 15 & Heterocyclic-Oxygen Compounds, Fused Ring $<9$ atoms \\
\hline 16 & Heterocyclic-Oxygen Compounds, Fused Ring \\
\hline 17 & Heterocyclic-Oxygen Compounds, Fused Ring 10 atoms \\
\hline 18 & Heterocyclic-Oxygen Compounds, Fused Ring $>10$ atoms \\
\hline 19 & Inter-Linked Heterocyclic-Oxygen Compounds \\
\hline 20 & Heterocyclic-Sulfur Compounds, Monocyclic Ring, $<5$ atoms \\
\hline 21 & Heterocyclic-Sulfur Compounds, Monocyclic Ring, \\
\hline 22 & Heterocyclic-Sulfur Compounds, Monocyclic Ring, $>5$ atoms \\
\hline 23 & Heterocyclic-Sulfur Compounds, Fused Ring \\
\hline 24 & Inter-Linked Heterocyclic-Sulfur Compounds \\
\hline 25 & Heterocyclic Sulfur-Oxygen Compounds, Monocyclic Ring \\
\hline 26 & Heterocyclic S-O Compounds, Fused Ring, S,O in same ring \\
\hline 27 & Heterocyclic S-O Compounds, Fused Ring, S,O in different ring \\
\hline 28 & Heterocyclic S-O Compounds, Non-Fused Ring, S, 0 in same ring \\
\hline 29 & Heterocyclic S-O Compounds, Non-Fused Ring, s, 0 in different ring \\
\hline 30 & Heterocyclic Selenium Compounds \\
\hline 31 & Heterocyclic Se-O Compounds \\
\hline
\end{tabular}

32 Heterocyclic Tellurium Compounds

33 Heterocyclic $\mathrm{Te}-\mathrm{O}$ Compounds

34 Heterocyclic Nitrogen Compounds, Monocyclic Ring, $<5$ atoms

$\begin{array}{lllll}\text { g } & 35 & \text { Heterocyclic Nitrogen Compounds, Monocyclic Ring, } 5 \text { atoms } \\ \mathrm{g} & 36 & \text { Heterocyclic Nitrogen Compounds, Monocyclic Ring, } 6 \text { atoms } \\ \mathrm{g} & 37 & \text { Heterocyclic Nitrogen Compound, Monocyclic Ring, } 6 \text { atoms } \\ & 38 & \text { Heterocyclic Nitrogen Compounds, Fused Ring, }>9 \text { atoms } \\ \text { h } & 39 & \text { Heterocyclic Nitrogen Compounds, Fused Ring, } 9 \text { atoms } \\ \text { h } & 40 & \text { Heterocyclic Nitrogen Compounds, Fused Ring, } 10 \text { atoms }\end{array}$


a used only in Bul1. Thermodynamics and Thermochem.

b merged with 3 for Bull T. T.

c merged with 4 for Bull T. T.

d merged with 11 for Bul1 T. T.

e merged with 15 for Bul1 T. T.

f merged with 20 for Bull T. T.

g merged with 34 for Bul1 T. T.

$\mathrm{h}$ merged with 38 for Bull T. T.

h 41 Heterocyclic Nitrogen Compounds, Fused Ring, >10 atoms

42 Inter-Linked Heterocyclic Nitrogen Compounds

43 Heterocyclic N-O Compounds, Fused Ring, N,O in same ring

44 Heterocyclic N-O Compounds, Fused Ring, N, O in different ring

45 Heterocyclic $\mathrm{N}-\mathrm{O}$ Compounds, Non-Fused Ring, N,O in same ring

46 Heterocyclic $\mathrm{N}-\mathrm{O}$ Compounds, Non-Fused Ring, N, O in different ring

47 Inter-Linked Heterocyclic Nitrogen-Oxygen Compounds

48 Heterocyclic N-S Compounds, Fused Ring, N, $\mathrm{S}$ in same ring

49 Heterocyclic N-S Compounds, Fused Ring, N, $S$ in different ring

50 Heterocyclic N-S Compounds, Non-Fused Ring, N,S in same ring

51 Heterocyclic $\mathrm{N}-\mathrm{S}$ Compounds, Non-Fused Ring, $\mathrm{N}, \mathrm{S}$ in different ring

52 Heterocyclic N-S-O Compounds, Monocyclic Ring

53 Heterocyclic N-S-O Compounds, Fused Ring

54 Heterocyclic Phosphorus Compounds

55 Heterocyclic Phosphorus-Oxygen Compounds

56 Heterocyclic P-S Compounds

57 Heterocyclic P-N Compounds

58 Heterocyclic P-O-S Compounds

59 Heterocyclic P-N-S Compounds

60 HeterocycIic P-N-O Compounds

61 Heterocyclic P-N-O-S Compounds

62 Heterocyclic As Compounds

63 Heterocyclic As-O Compounds

64 Heterocyclic Sb Compounds

65 Heterocyclic Sb-0 Compounds

66 Heterocyclic Bi Compounds

67 Heterocyclic $\mathrm{Bi}-\mathrm{O}$ Compounds 
70 Dyes

71 Natural and Synthetic Rubber

72 Natural and Synthetic Plastics and Resins

73 Natural and Synthetic Fibers

74 Alkaloids

75 Vitamins and Vitamin Related Compounds

76 Steroids

77 Monosaccharides

78 Disaccharides and Other Oligosaccharides

79 Polysaccharides

80 Miscellaneous I

81 Miscellaneous II

82 Miscellaneous III

83 Miscellaneous IV

84 Miscellaneous V

85 Miscellaneous VI

a 99 General (unclassified) 
Nationa1 Bureau of Standards

Chemical Thermodynamics Data Group

Tentative List (1972) of

\section{Organic Compound Group Classes}

040 Hydrocarbons (genera1)

050 Saturated Hydrocarbons (alkanes or cycloalkanes)

052 Saturated Hydrocarbons (Bicycloalkanes

054 Saturated Hydrocarbons (polycycloalkanes)

056 Saturated Hydrocarbons (alkyl subst. cycloalkanes <5 C atoms)

058 Saturated Hydrocarbons (alky1 subst. cycloalkanes 5 C atoms)

060 Saturated Hydrocarbons (alky1 subst. cycloalkanes $6 \mathrm{C}$ atoms)

062 Saturated Hydrocarbons (alky1 subst. cycloalkanes $>6 \mathrm{C}$ atoms)

068 Miscellaneous Saturated Hydrocarbons

070 Unsaturated Hydrocarbons (alkenes or cycloalkenes)

072 Unsaturated Hydrocarbons (alkyl subst. cycloalkenes)

074 Unsaturated Hydrocarbons (bicycloalkenes)

076 Unsaturated Hydrocarbons (polycycloalkenes)

078 Unsaturated Hydrocarbons (dialkenes or cyclodialkenes)

080 Unsaturated Hydrocarbons (polyalkenes or cyclopolyalkenes)

082 Unsaturated Hydrocarbons (alkynes or cycloalkynes)

084 Unsaturated Hydrocarbons (dialkynes)

086 Unsaturated Hydrocarbons (polya1kynes)

088 Unsaturated Hydrocarbons (cyclo(alkene-alkynes))

090 Unsaturated Hydrocarbons (di (a 1kene-alkynes))

092 Unsaturated Hydrocarbons (poly(alkene-alkynes))

094 Miscellaneous Unsaturated Hydrocarbons

096 Inter-Linked (Catenated) alicyclic ring systems (saturated)-(chains)

098 Inter-Linked (Catenated) alicyclic ring systems (unsaturated)-(chains)

100 Inter-Linked (Catenated) alicyclic ring systems (miscellaneous)-(chains)

102 Intra-Linked alicyclic ring systems (saturated)

104 Intra-Linked alicyclic ring systems (unsaturated)

106 Intra-Linked alicyclic ring systems (miscellaneous)

110 Benzene, Naphthalene and Polynuclear Parent Hydrocarbons

112 Alkane substituted aromatic hydrocarbons

114 Alkene substituted aromatic hydrocarbons

116 Alkyne substituted aromatic hydrocarbons

118 Alicyclic substituted aromatic hydrocarbons

120 Catenated aromatic ring systems (chains)

124 Partia11y Hydrogenated aromatic hydrocarbons

128 Miscellaneous aromatic hydrocarbons

Note: polyfunctional compounds are classed under the highest applicable number. 
130 Saturated primary alcohols*

132 Saturated secondary alcohols

134 Saturated tertiary alcohols

136 Saturated diols alcohols

138 Saturated polyols alcohols

140 Unsaturated alcohols

142 Phenolic Compounds

144 Miscellaneous alcohols

148 Saturated Ethers or Sulfides

150 Unsaturated Ethers or Sulfides

152 Hydroxy Ethers or Sulfides

158 Miscellaneous Ethers or Sulfides

162 Peroxides or Polysulfides

164 Ozonides

166 Hemiacetals

168 Acetals

170 Orthoesters

174 Saturated Aldehydes

176 Unsaturated Aldehydes

178 Miscellaneous Aldehydes

180 Saturated Ketones

182 Unsaturated Ketones

184 Quinones

186 Miscellaneous Ketones

190 Monobasic Saturated Acids

192 Monobasic Unsaturated Acids

194 Monobasic Hydroxy and Keto Acids

196 Polybasic Saturated Acids

198 Polybasic Unsaturated Acids

200 Polybasic Hydroxy and Keto Acids

202 Miscellaneous Acids

204 Carbonic Acid Derivatives

206 Peroxy Acids

208 Acid Anhydrides

210 Lactones

212 Lactides

215 Acid Halides

220 Saturated Methyl Esters

221 Unsaturated Methyl Esters

222 Hydroxy and Keto Methyl Esters

*Note: Functional $\mathrm{S}, \mathrm{Se}, \mathrm{Te}$ is put in the same subclass as the corresponding oxygen function throughout the scheme. 
Saturated Ethyl Esters

225 Unsaturated Ethyl Esters

226 ifjdroxy and Keto Ethyl Esters

228 Saturated Aliphatic Esters

229 Unsaturated Aliphatic Esters

230 Hydroxy and Keto Aliphatic Esters

232 Saturated Alicyclic Esters

233 Unsaturated Alicyclic Esters

234 Hydroxy and Keto Alicyclic Esters

236 Aromatic Esters

238 Miscellaneous Esters

240 Carbonates

242 Salts of Aliphatic Acids

243 Salts of Alicyclic Acids

244 Salts of Aromatic Acids

245 Miscellaneous Salts

250 Sulfoxides

258 Sulfones

266 Sulfinic Acids $\mathrm{RSO}_{2} \mathrm{H}$

268 Sulfonic Acids $\mathrm{RSO}_{3} \mathrm{H}$

270 Sulfenyl Halides RSX

272 Sulfinyl Halides RSOX

274 Sulfonyl Halides $\mathrm{RSO}_{2} \mathrm{X}$

276 Thionic Acids RCSOH

278 Thiolic Acids RCOSH

280 Esters of Sulfenic Acids RSOR'

282 Esters of Sulfinic Acids $\mathrm{RSO}_{2} \mathrm{R}^{\prime}$

284 Esters of Sulfonic Acids $\mathrm{RSO}_{3} \mathrm{R}^{\prime}$

286 Esters of Thionic Acids RCSOR'

288 Esters of Thiolic Acids RCOSR'

290 Esters of Sulfuric Acids $\mathrm{RHSO}_{4}, \mathrm{R}_{2} \mathrm{SO}_{4}$

292 Esters of Sulfurous Acids $\mathrm{RHSO}_{3} \mathrm{R}_{2} \mathrm{SO}_{3}$

294 Miscellaneous C-H-S- Compounds

296 Miscellaneous C-H-S-O Compounds 


\begin{tabular}{|c|c|}
\hline 300 & Primary Amines \\
\hline 302 & Secondary Amines \\
\hline 304 & Tertiary Amines \\
\hline 306 & Quaternary Amines \\
\hline 308 & Amine Salts \\
\hline 310 & Diamines \\
\hline 312 & Triamines \\
\hline 314 & Tetraamines and Higher Amines \\
\hline 316 & Amine-Acid Complexes (EDTA) \\
\hline 340 & Miscellaneous Amines \\
\hline 342 & Nitriles \\
\hline 344 & Miscellaneous Nitriles \\
\hline 346 & Carbylamines \\
\hline 348 & Miscellaneous Carbylamines \\
\hline 350 & Azides \\
\hline 352 & Imines \\
\hline 354 & Cyanamides \\
\hline 356 & Amidines \\
\hline 358 & Substituted Hydrazines or Hydrazo Compounds \\
\hline 360 & Hydrazones \\
\hline 362 & Guanidine and its Derivatives \\
\hline 364 & Diazonium Compounds \\
\hline 366 & Purine and its Derivatives \\
\hline 368 & Quinoline and its Derivatives \\
\hline 370 & Azo Compounds \\
\hline 380 & Miscellaneous $\mathrm{C}-\mathrm{H}-\mathrm{N}$ Compounds \\
\hline 382 & Amino Acids \\
\hline 384 & Amino Acids Containing a Pheny 1 Group \\
\hline 386 & Dipeptides \\
\hline 388 & Tripeptides \\
\hline 390 & Polypeptides \\
\hline 392 & Proteins \\
\hline 394 & Miscellaneous Amino Acids. \\
\hline
\end{tabular}


$400 \quad$ Amides

404 Miscellaneous Amides

410 Urea Derivatives

420 Miscellaneous Urea Derivatives

430 Nitro Compounds

432 Nitro Aldehydes

433 Nitro Alcohols

434 Nitro Ethers

436 Nitro Acids

438 Nitro Amides

440 Nitro Amines

442 Nitro Ketones

444 Nitro Esters

446 Nitro Phenols

448 Miscellaneous Nitro Compounds

450 Hydroxylamines

452 Aldoximes

454 Ketoximes

456 Imides

458 Lactams

460 Nitramines

462 Nitroso Compounds

464 Nitrosamines

466 Cyanates

468 Isocyanates

470 Nitrites $\mathrm{RNO}_{2}$

472 Nitrates $\mathrm{RNO}_{3}$

474 Semicarbazides

476 Osazones

478 Amine Oxides

482 Carbamates and Their Derivatives

490 Nitro Dyes

492 Nitroso Dyes

494 Azo Dyes

496 Triphenylmethane Dyes

498 Phthalein Dyes

500 Anthraquinone Dyes

502 Indigo Dyes

504 Sulfur Dyes

506 Auramine Dyes

508 Azine, Thiazine and Oxazine Dyes

510 Anthocyanins and Flavones

512 Phthalocyanine Dyes

514 Miscellaneous Dyes 
520 Miscellaneous $\mathrm{C}-\mathrm{H}-\mathrm{N}-\mathrm{O}$ Compounds

530 Diaminosulfides and Their Derivatives, $\mathrm{H}_{2} \mathrm{~N}-\mathrm{S}-\mathrm{NH}_{2}$

532 Sulfenamides $\mathrm{R}-\mathrm{S}-\mathrm{N}-\mathrm{H}_{2}$

534 Miscellaneous $\mathrm{C}-\mathrm{H}-\mathrm{N}-\mathrm{S}$ Compounds

540 Sulfinamides $\mathrm{RSONH}_{2}$

542 Sulfonamides $\mathrm{RSO}_{2} \mathrm{NH}_{2}$

544 Sulfamide and its Derivatives $\mathrm{H}_{2} \mathrm{~N}-\mathrm{SO}_{2}-\mathrm{NH}_{2}$

546 Sulfamates $\mathrm{RSO}_{3} \mathrm{NH}_{2}$

548 Aminosulfinates

550 Aminosulfonates

554 Nitrosulfonates

556 Amine Disulfinic Acids and Their Derivatives

558 Amine Trisulfinic Acids and Their Derivatives

560 Amine Disulfonic Acids and Their Derivatives

562 Amine Trisulfonic Acids and Their Derivatives

568 Miscellaneous $\mathrm{C}-\mathrm{H}-\mathrm{N}-\mathrm{O}-\mathrm{S}$ Compounds

580 Phosphines

582 Phosphine Oxides

590 Miscellaneous C-H-P Compounds

600 Substituted Phosphinic Acids $\mathrm{R}_{2} \mathrm{PO}(\mathrm{OH})$

602 Substituted Phosphonic Acids RPO(OH) 2

604 Phosphites

606 Phosphates

608 Esters of Phosphinic Acids

610 Esters of Phosphonic Acids

616 Miscellaneous C-H-P-O Compounds

620 Miscellaneous C-H-P-S Compounds

630 Miscellaneous CHPN Compounds

640 Miscellaneous CHPSO Compounds

650 Miscellaneous CHPNO Compounds

660 Miscellaneous CHPSN Compounds

670 Miscellaneous CHPOSN Compounds

700 Arsines

702 Arsenites

704 Arsenates

706 Miscellaneous CHAs Compounds

708 Miscellaneous CHAsO Compounds 
712 Stibnites

714 Stibnates

716 Miscellaneous CHSb Compounds

718 Miscellaneous CHSbO Compounds

720 Bismuthines

722 Bismuthates

724 Miscellaneous CHBi Compounds

726 Miscellaneous CHBiO Compounds

\section{APPENDIX E}

This sequence, in which the elements have the same order as in the Standard Order of Arrangement (see NBS TN 270-3), is used on Bulletin Tapes. The numbers are different because deuterium and tritium are assigned their own numbers, there is a generalized halogen (16) and a generalized lanthanide (83), and allowance has been made for elements 105 and 106. A compound is filed (or appears on the tape) under its constituent element having the highest finding number. 


\begin{tabular}{|c|c|c|c|c|c|c|c|}
\hline 1 & 0 & 31 & B & 61 & [106] & 91 & Am \\
\hline 2 & $\mathrm{H}$ & 32 & AI & 62 & Ti & 92 & $\mathrm{Pu}$ \\
\hline 3 & D & 33 & $\mathrm{Ga}$ & 63 & $\mathrm{Zr}$ & 93 & $\mathrm{~Np}$ \\
\hline 4 & $T$ & 34 & In & 64 & $\mathrm{Hf}$ & 94 & U \\
\hline 5 & $\mathrm{He}$ & 35 & $\mathrm{~T} 1$ & 65 & $\mathrm{Ku}$ [104] & 95 & $\mathrm{~Pa}$ \\
\hline 6 & $\mathrm{Ne}$ & 36 & $\mathrm{Zn}$ & 66 & Sc & 96 & Th \\
\hline 7 & $\mathrm{Ar}$ & 37 & $\mathrm{Cd}$ & 67 & $\mathrm{Y}$ & 97 & Ac \\
\hline 8 & $\mathrm{Kr}$ & 38 & $\mathrm{Hg}$ & 68 & $\mathrm{Lu}$ & 98 & $\mathrm{Be}$ \\
\hline 9 & $\mathrm{Xe}$ & 39 & $\mathrm{Cu}$ & 69 & $\mathrm{Yb}$ & 99 & $\mathrm{Mg}$ \\
\hline 10 & $\mathrm{Rn}$ & 40 & $\mathrm{Ag}$ & 70 & $\operatorname{Tm}$ & 100 & $\mathrm{Ca}$ \\
\hline 11 & F & 41 & $\mathrm{Au}$ & 71 & Er & 101 & $\mathrm{Sr}$ \\
\hline 12 & $\mathrm{Cl}$ & 42 & $\mathrm{Ni}$ & 72 & Ho & 102 & $\mathrm{Ba}$ \\
\hline 13 & $\mathrm{Br}$ & 43 & Co & 73 & Dy & 103 & $\mathrm{Ra}$ \\
\hline 14 & I & 44 & $\mathrm{Fe}$ & 74 & $\mathrm{~Tb}$ & 104 & $\mathrm{Li}$ \\
\hline 15 & At & 45 & $\mathrm{Pd}$ & 75 & Gd & 105 & $\mathrm{Na}$ \\
\hline 16 & $X$ (halogen) & 46 & $\mathrm{Rh}$ & 76 & Eu & 106 & $\mathrm{~K}$ \\
\hline 17 & $\mathrm{~s}$ & 47 & $\mathrm{Ru}$ & 77 & $\mathrm{Sm}$ & 107 & $\mathrm{Rb}$ \\
\hline 18 & $\mathrm{Se}$ & 48 & Pt & 78 & Pm & 108 & Cs \\
\hline 19 & $\mathrm{Te}$ & 49 & Ir & 79 & Nd & 109 & Fr \\
\hline 20 & Po & 50 & Os & 80 & $\operatorname{Pr}$ & 110 & \\
\hline 21 & $\mathrm{~N}$ & 51 & Mn & 81 & $\mathrm{Ce}$ & & \\
\hline 22 & $P$ & 52 & Tc & 82 & La & & \\
\hline 23 & As & 53 & $\operatorname{Re}$ & 83 & Ln $(\operatorname{lan} t)$ & les) & \\
\hline 24 & $\mathrm{Sb}$ & 54 & $\mathrm{Cr}$ & 84 & No & & \\
\hline 25 & $\mathrm{Bi}$ & 55 & Mo & 85 & Md & & \\
\hline 26 & C & 56 & W & 86 & $\mathrm{Fm}$ & & \\
\hline 27 & Si & 57 & [105] & 87 & Es & & \\
\hline 28 & $\mathrm{Ge}$ & 58 & V & 88 & $\mathrm{Cf}$ & & \\
\hline 29 & $\mathrm{Sn}$ & 59 & $\mathrm{Nb}$ & 89 & $\mathrm{Bk}$ & & \\
\hline 30 & $\mathrm{~Pb}$ & 60 & $\mathrm{Ta}$ & 90 & $\mathrm{Cu}$ & & \\
\hline
\end{tabular}


Codes used to indicate variable composition compounds, alloys, mixtures, entities in equations, hydrates and ions.

These flags follow the number of atoms of the last element in the compound, e.g. In words 7-12 for the first component. That a flag code is stored can be determined by examining the element symbol storage field, e.g. words 1-6, where the corresponding region is set to zero.

000 compound (norma1)

001 compound is a hydrate. The next byte stores the no. of molecules of water

002 compound occurs in a chemical equation

003 "dash" indicates a component of a mixture

004 compound is of variable composition, e.g. $\mathrm{Fe}^{3+}: \mathrm{Cl}^{-}$indicates the group of compounds $\mathrm{Fe}_{\mathrm{n}} \mathrm{Cl} \mathrm{l}_{\mathrm{m}}$

005 "slash" indicates an alloy, e.g. Al/Sn

010 "w" excitation or activated state

011 " + " formal positive charge or oxidation state

the next byte $s$ tores the number of charges

012 "-" formal negative charge

the next byte stores the number of chargea

Note: When more than one flag appears, they are tored in descending numberical order. 


\section{Display of Data Recording ("Dump")}

The first few physical records from two of the files on the Bulletin No. 14 (1971) tape are displayed here in a printer dump. These show every character recorded, both controls and graphics. The explanation of the conventions used in the dump follows the examples.

Example 1. Header Labels - the first three physical records on the tape.

Example 2. File 非 1 - first two physical records. The valid data start at the mark in the ninth line of Block 1 . The first valid entry corresponds to the first entry in figure $1 b$ Substance-property index.

Example 3. Header labels for File 4.

Example 4. File \# 4 - first physical record. The data correspond exactly to the start of figure la - Bibliography. 
Example 1

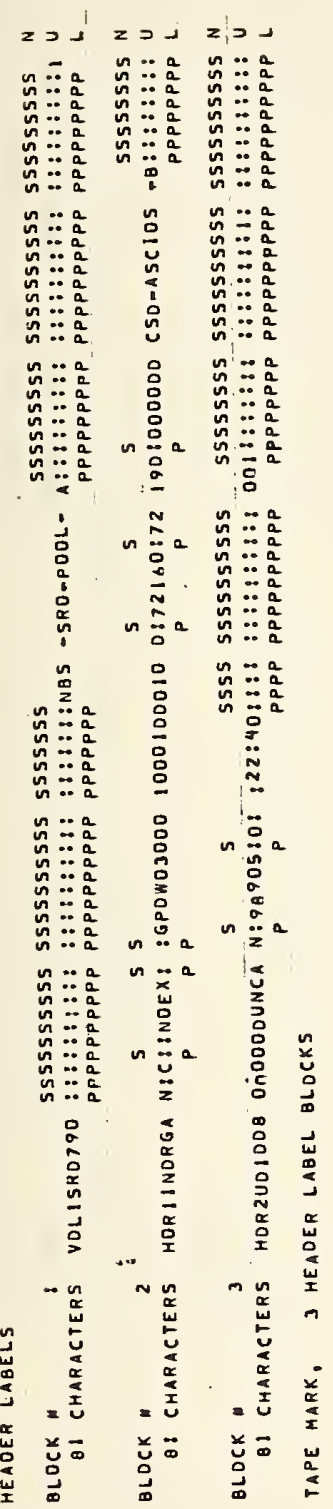


Example 2

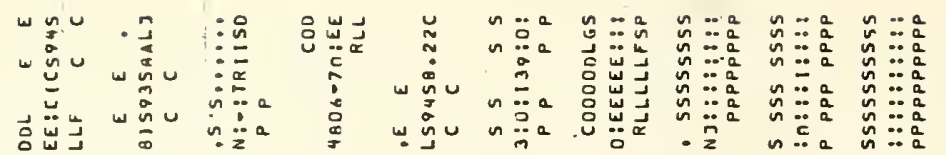

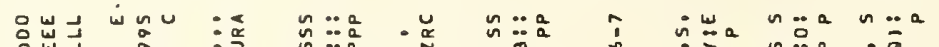

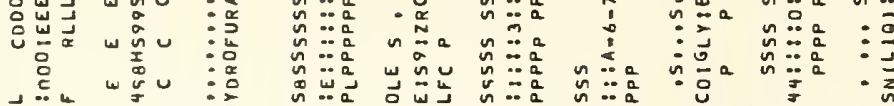

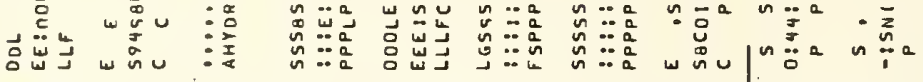

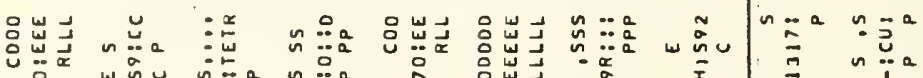

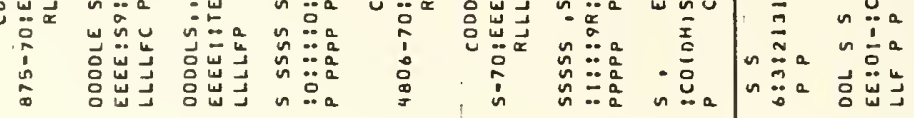

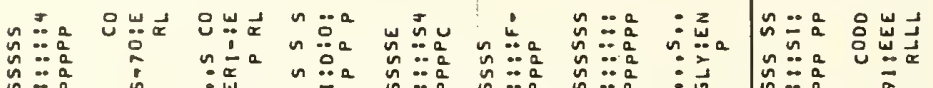

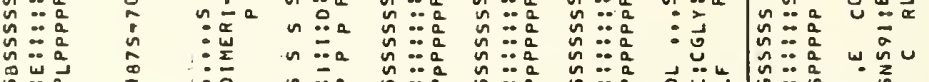

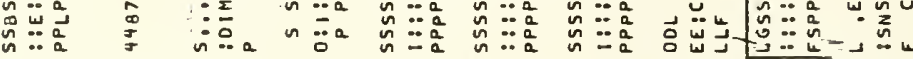

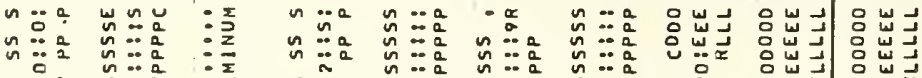

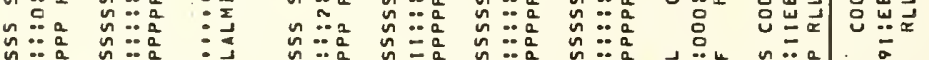

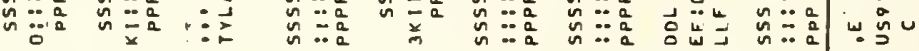

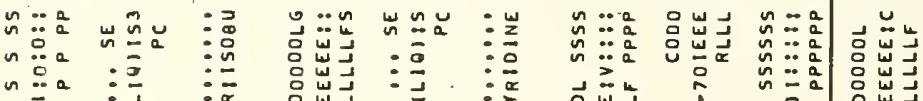

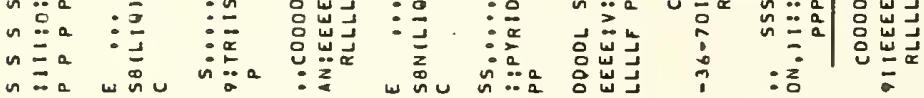

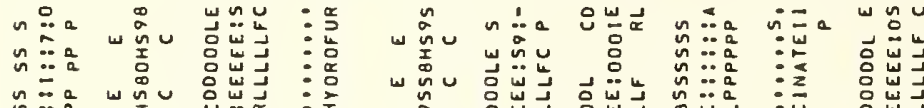

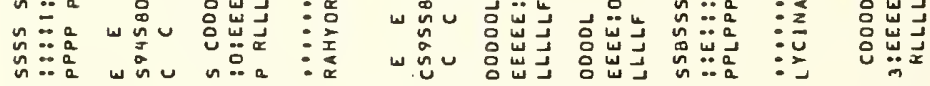

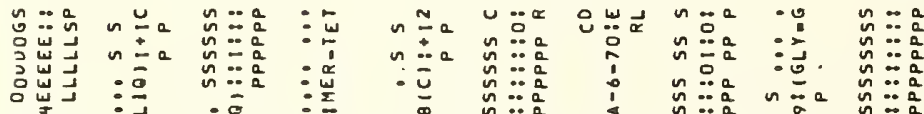

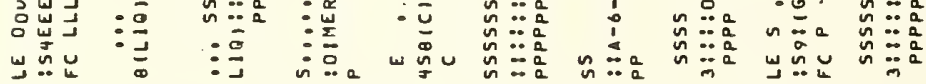

嵒

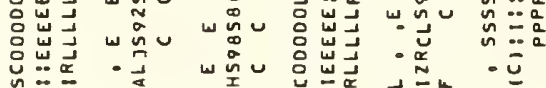

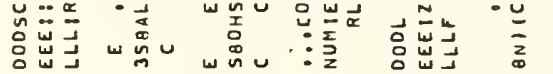

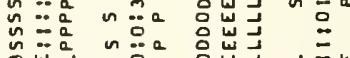

至

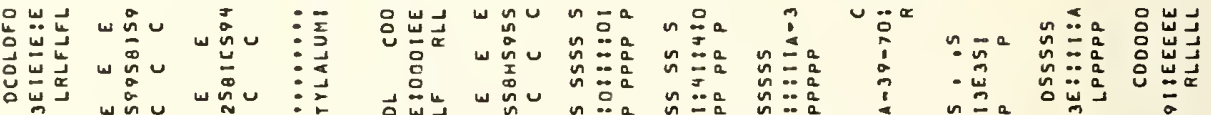

苟

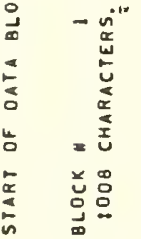

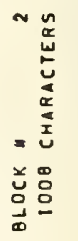




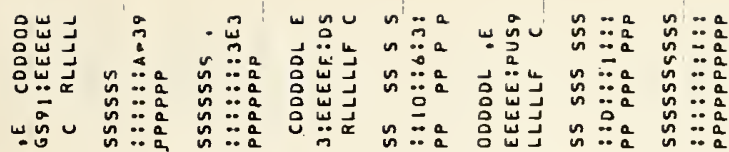

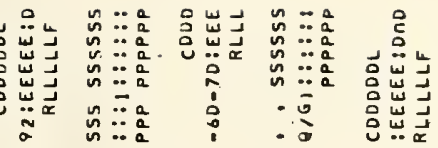

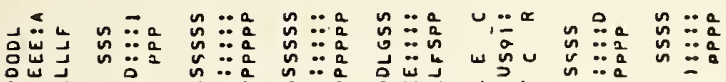

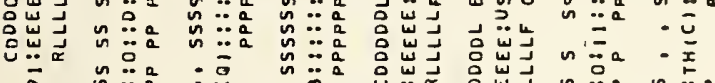

a $n$..

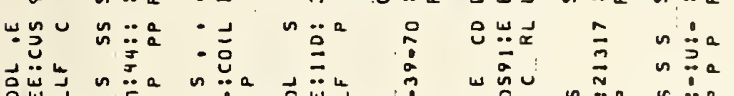

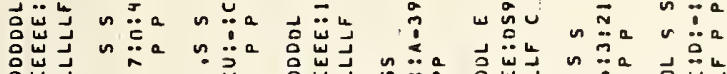

总出

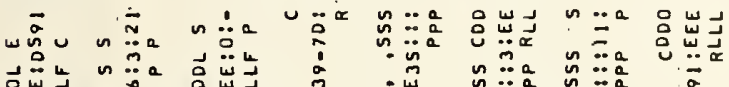

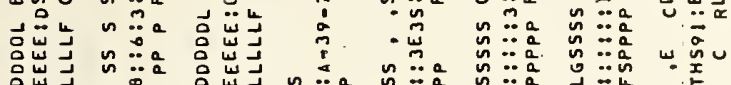

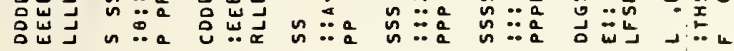

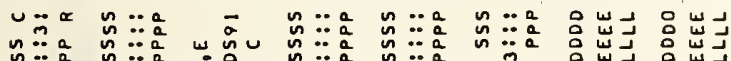

n̋:

出::a

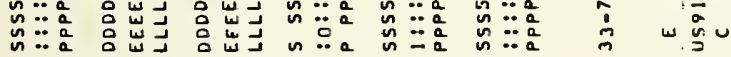

n $\because$ 落 $a$ \&

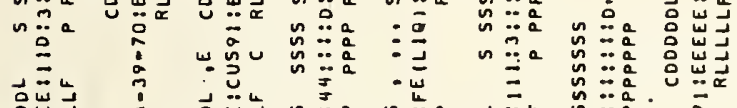

啒山 u

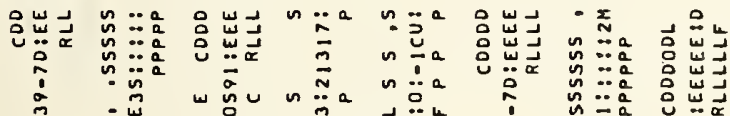

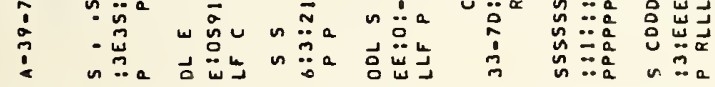

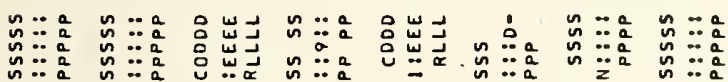

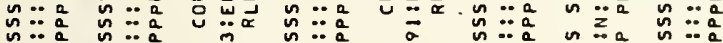

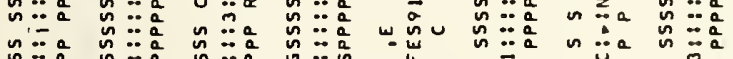

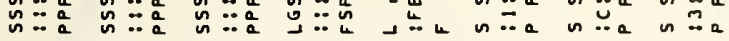

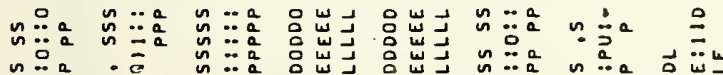

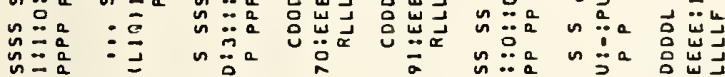

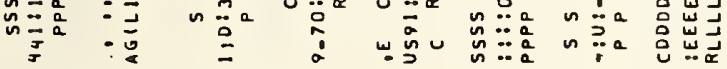

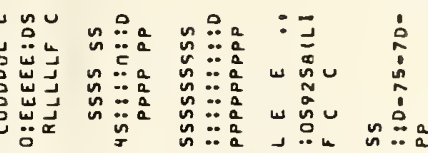

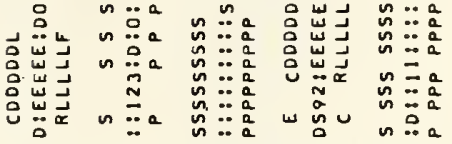

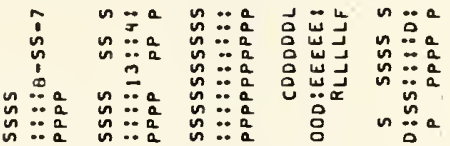

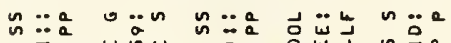

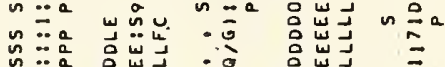

出:湜

出:流品

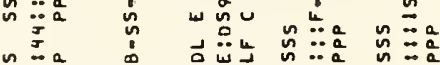

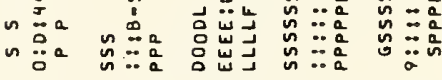

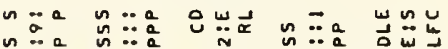

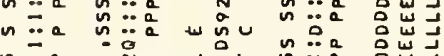

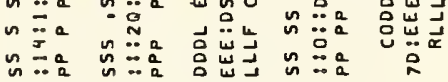

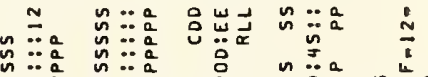

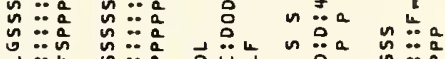

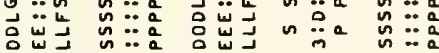

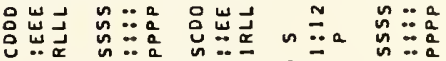

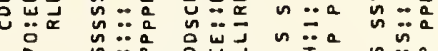

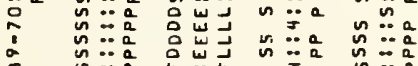

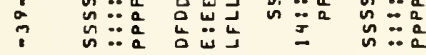

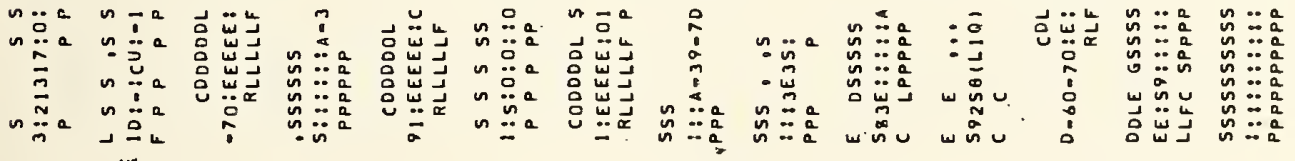

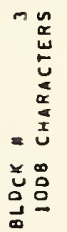


Example 3

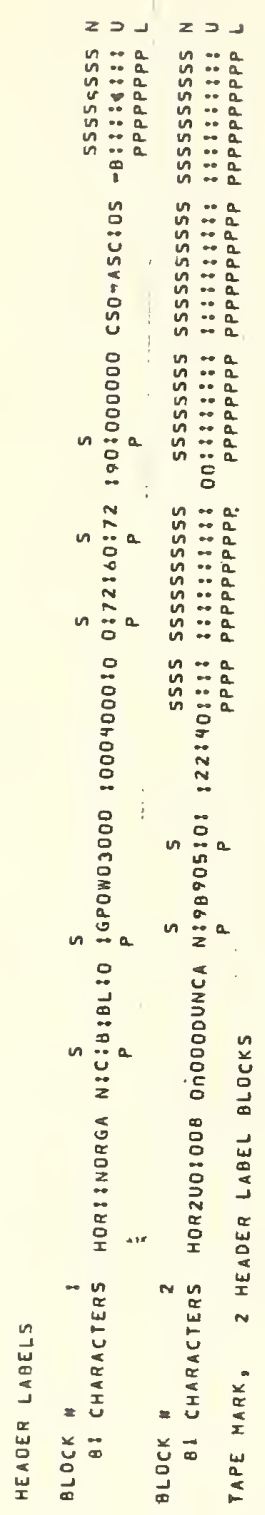




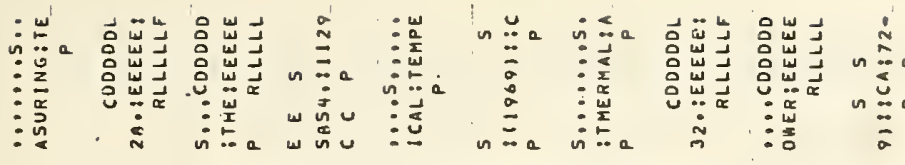

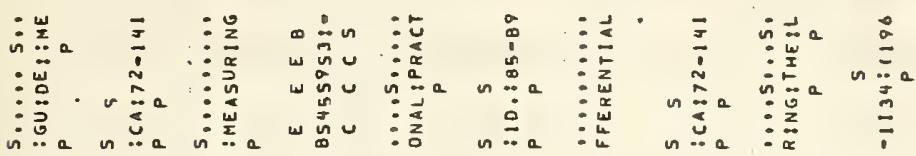

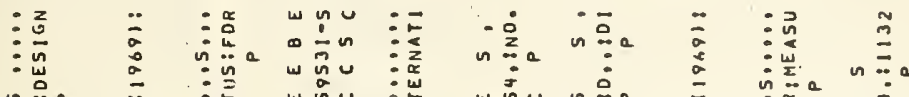

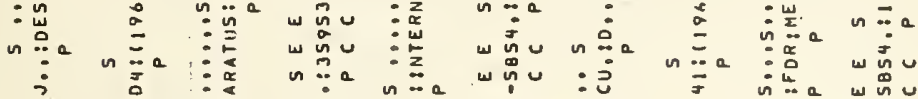

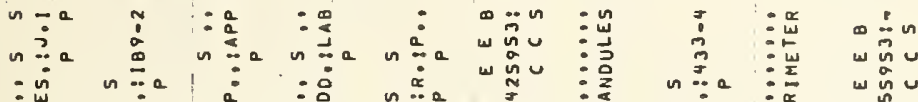

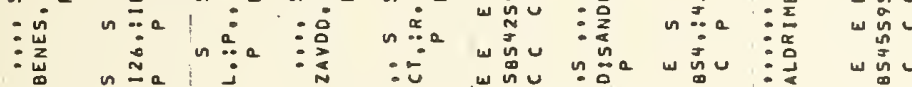

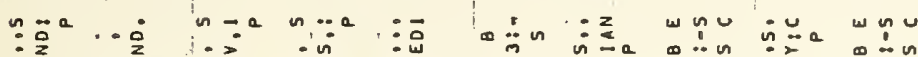

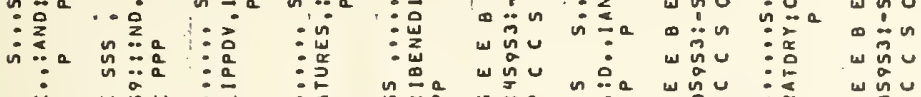

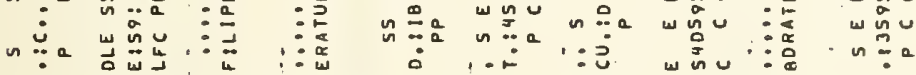

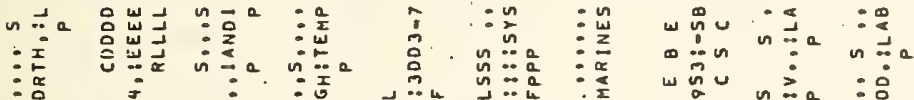

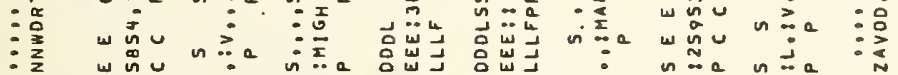

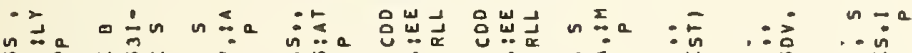

$\begin{array}{llllll} & \\ 0\end{array}$

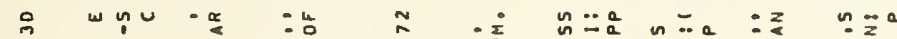

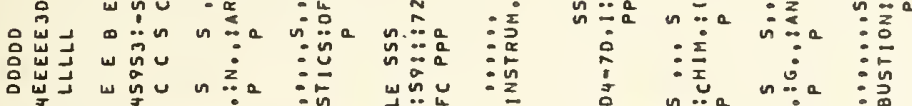

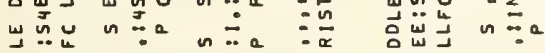

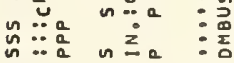

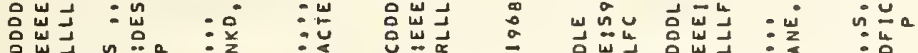

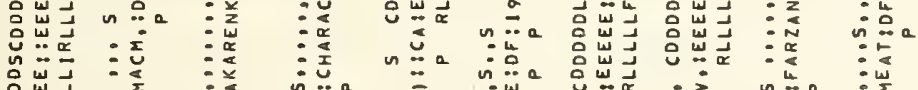

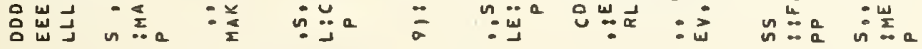

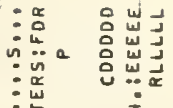

演垔

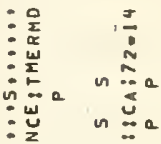

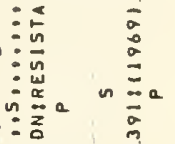

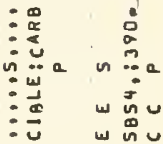

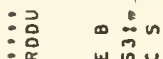

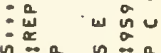

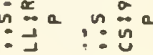

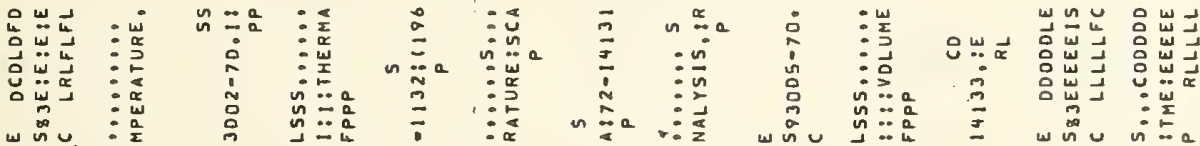

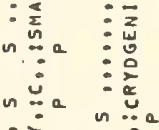

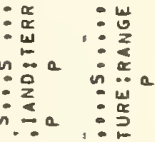

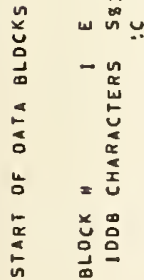

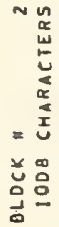


This character by character "dump" was prepared on a printer that has a limited character repertory. This consists of space and 60 of the characters in columns 2 through 4 of the ASCII table plus two special graphics. One of these, Greek capital $\Delta$, is used in the dump to show double quotes, circumflex and underscore.

The dump has messages showing the number and size of each physical block. Then the text of each block is shown, in groups of ten characters. This is a "three level dump". ASCII controls are indicated by their mnemonics written vertically:

$\begin{array}{llllll}\text { E } & \text { B } & \text { D } & \text { S } & \text { S } & \text { C } \\ \text { S } & \text { S } & \text { E } & : & : & : \\ \text { C } & \text { P } & \text { L } & \text { P } & \text { I } & \text { R }\end{array}$

Note that a colon is inserted in two letter mnemonics.

Letters, numerals and speclal characters are written in clear text. A comma above an ASCII character means that it should be read as the corresponding character from columns 6 and 7, e.g. lowercase for letters. This usage and that for $\Delta$ is shown below

A means a (used for all letters)

)

$\triangle$ means " (quote)

*

$\triangle$ means (circumflex)

$+\quad$ means underscore

$\dot{\Delta}$ means $\sim($ tilde $)$ 
Each line is recorded from left to right in a three level line (superscript, main line, and subscript). The lines are of variable length and are closed by carriage returns.

\section{Figure Captions}

1. Samples of Printed Text of the Bulletin.

a. Bibliography. Top of page 320, Bull. Thermodyn. Thermochem. 141971 .

b. Substance-Property Index. Top of page 184, Bul1. Thermodyn. Thermochem. 141971 .

2. Example of a Substance-Property Index Entry as it, appears on the Bulletin Tapes. See Section 3 for an explanation.

3. File Structure on the Bulletin Tapes, showing Labels (VOL 1, HDR 1, HDR 2, EOF 1, EOF 2), Tape marks (TM) and positions of files. See section 4 for explanation.

4. Character set (ASCII plus an alternative graphic set) used on GPDWO3 tapes. The numerical value for a character is an elght bit number based on the position of the character in the table: value $=16 *$ Column + Row (Space, $2 / 0=32 ; N, 4 / 14=78)$. Printout from a teletypewriter equipped with red-ribbon shift but not with the alternative graphic set would show (in red) the corresponding character from the standard set. 


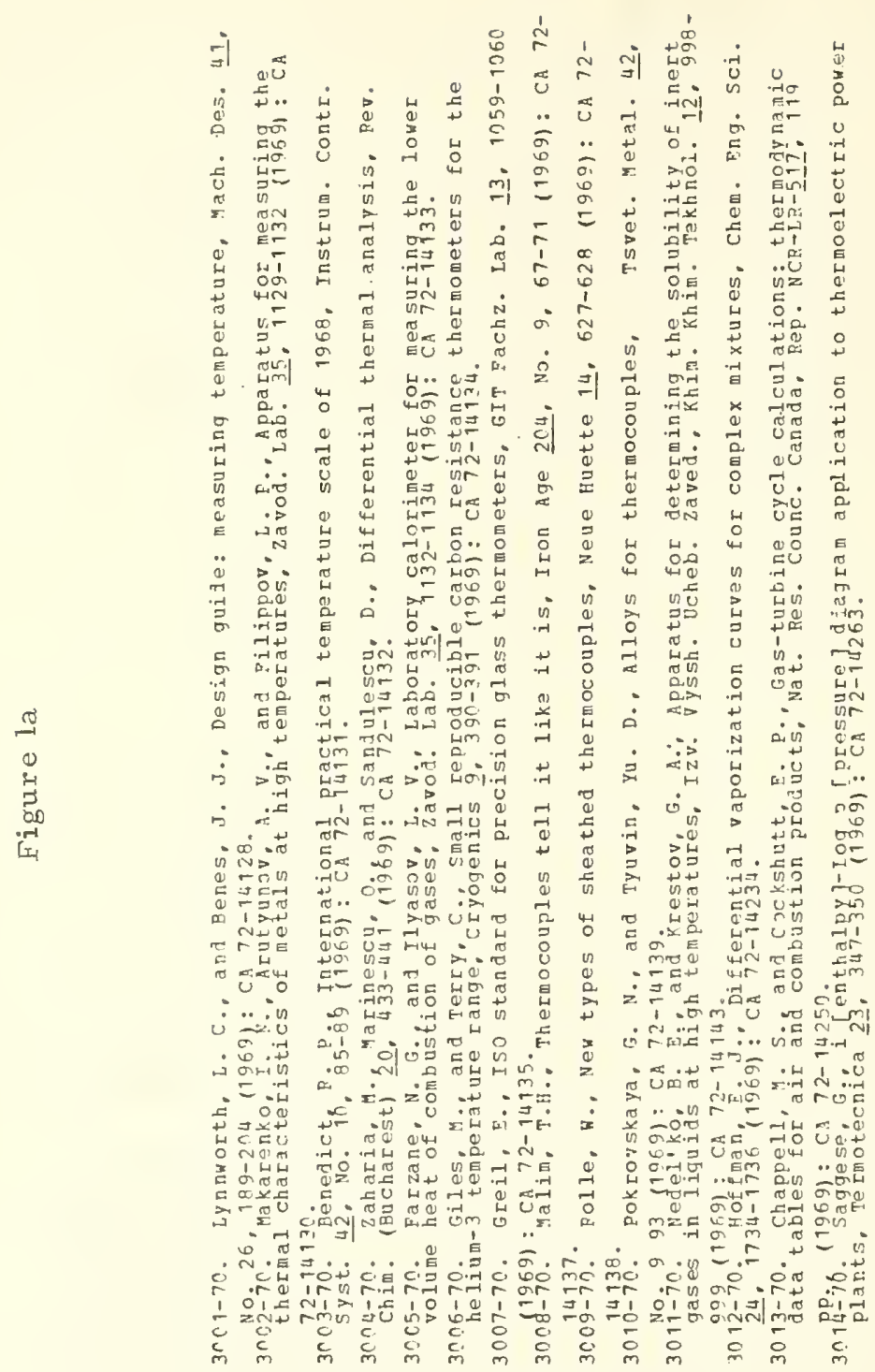




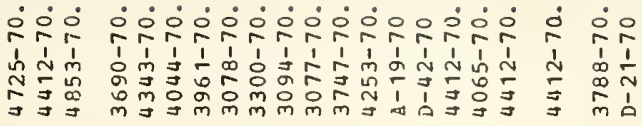

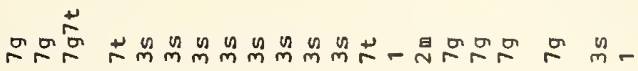

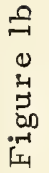

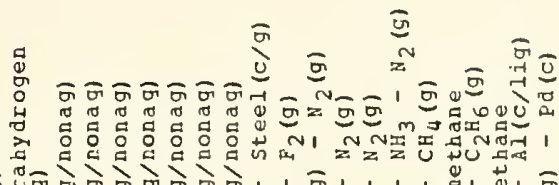

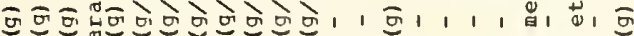

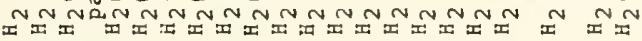

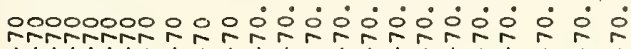

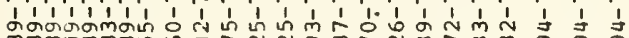
mimmm

$\cos \cos n$

minmma

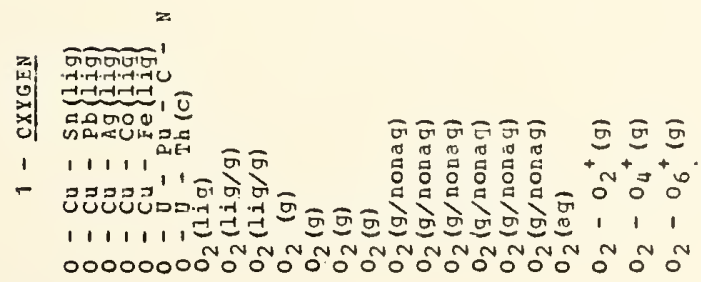


Figure 2. Liample of a substance-property index entry as it appears on the sulletin Tape. See Chapter $\ddot{j}$ for an explanation.

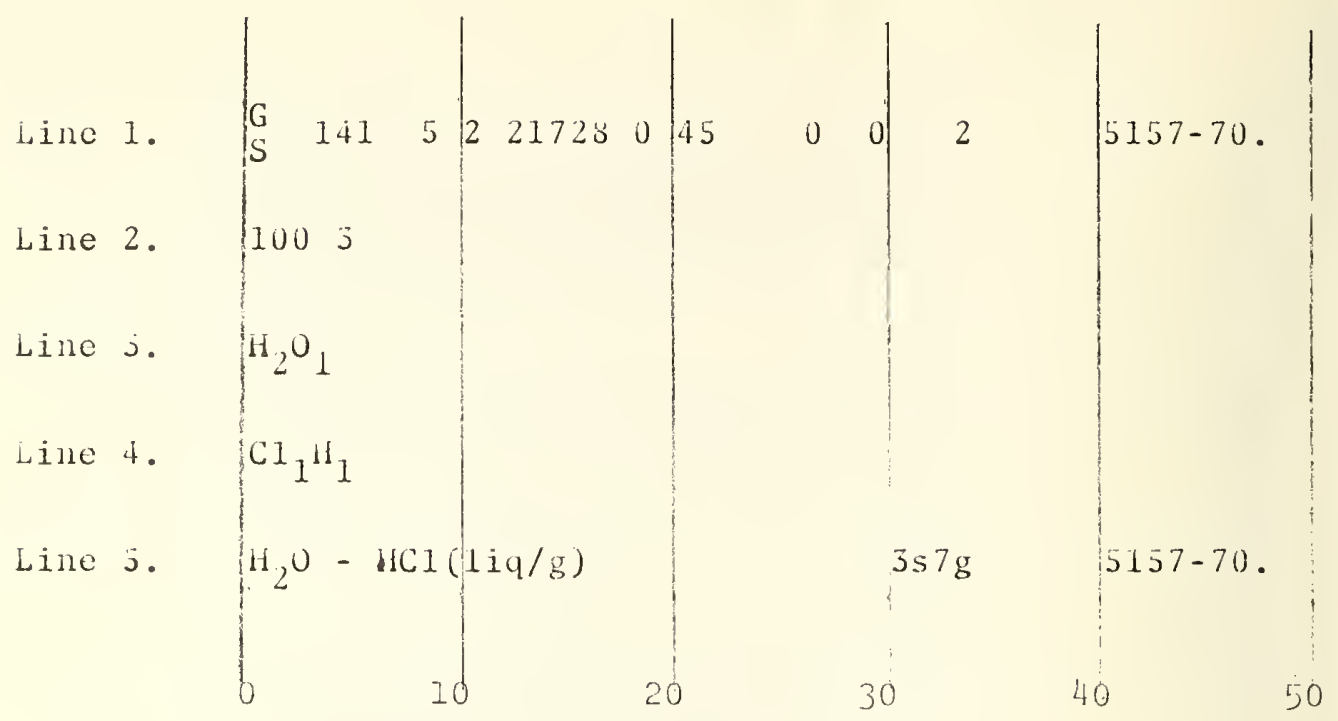


FIGURE 3. STRUCTURE OF THE TAPE SHOWING POSITIONS

OF LABELS, TAPE MARKS AND FILES

VOL 1

81 characters

HDR 1

HDR 2

(TM)

File $1 \quad$ Blocks of 1008 char.

(TM)

EOF 1

81 characters

EOF 2

(TM)

H DR 1

HDR 2

(TM)

File 2

(TM)

•

HDR 1

HDR 2

(TM)

File 6 (Last)

(TM)

EOF 1

EOF 2

(TM)

(TM) 


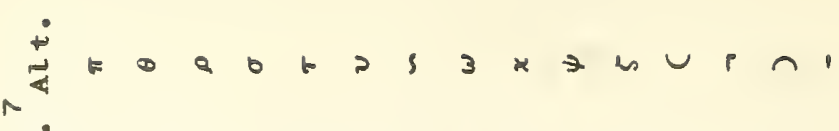

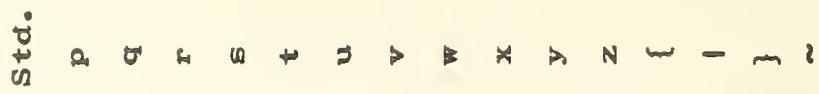

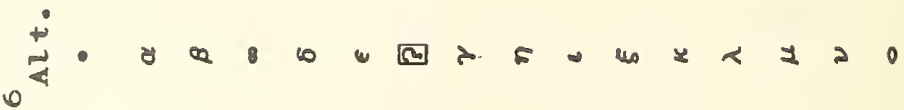

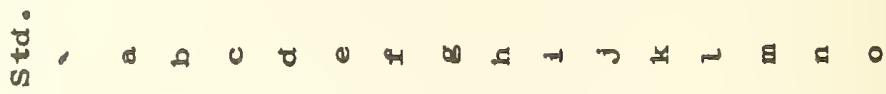

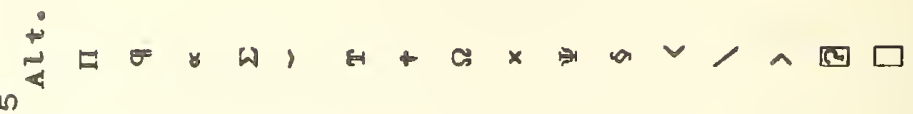

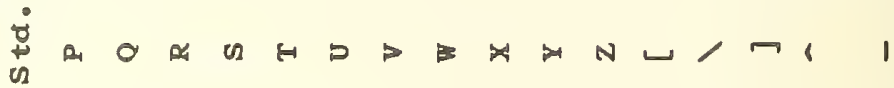

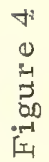

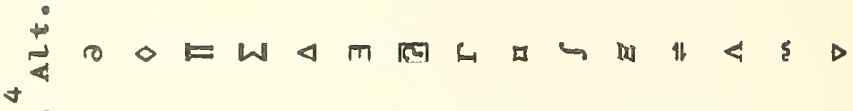

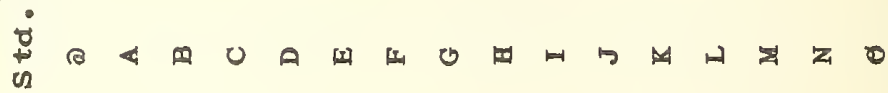

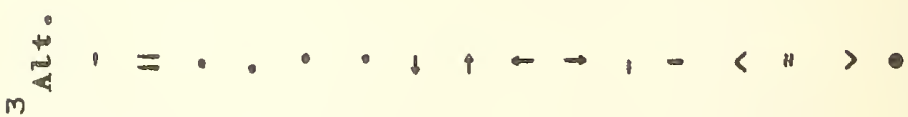

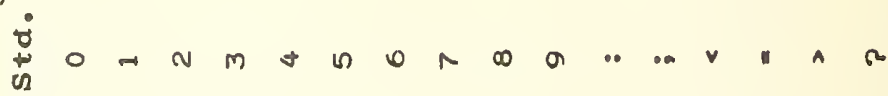

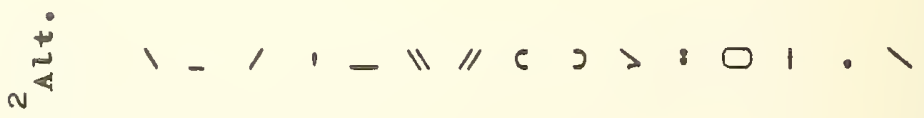
i⿱

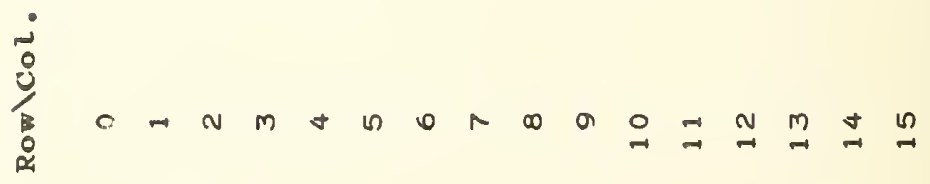


FORM NBS.114A $(1.71)$

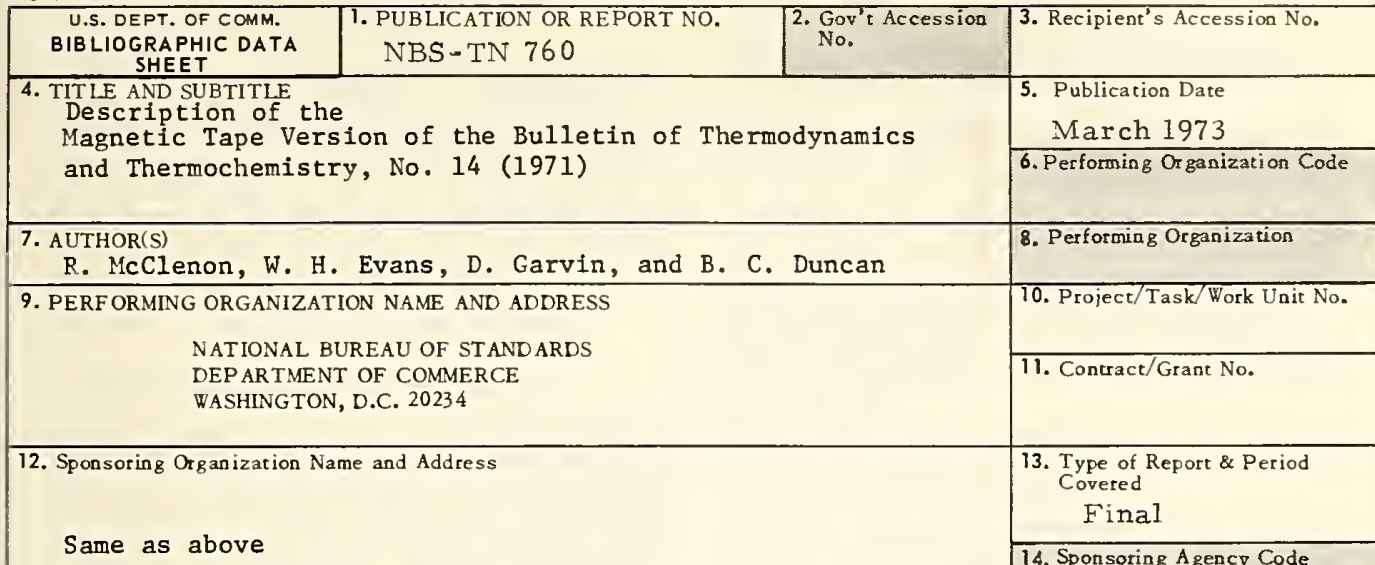

15. SUPPLEMENTARY NOTES

16. ABSTRACT (A 200-wotd or less factual summary of most significant information. If document includes a significant biblio graphy or literature survey, mention it here.)

The substance-property index and bibliography sections of the Bulletin of Thermodynamics and Thermochemistry, No. 14 (May 1971) have been converted to a magnetic tape version designed for computerized searching written in an extended form of the American National Standard Code for Information Interchange (X 3.4-1968). In this version each substance-property entry has been supplemented by a searching key. This report describes the magnetic tape version.

17. KEY WORDS (Alphabetical order, separated by semicolons)

Bibliography; chemical thermodynamics; extended character codes; information retrieval; magnetic tape

18. AVAILABILITY STATEMENT

XX UNLIMITED.

FOR OFFICIAL DISTRIBUTION. DO NOT RELEASE TO NTIS.

\begin{tabular}{|l|c|}
$\begin{array}{l}\text { 19. SECURITY CLASS } \\
\text { (THIS REPORT) }\end{array}$ & 21. NO. OF PAGES \\
& 51 \\
UNCL ASSIFIED & \\
\hline $\begin{array}{l}\text { 20. SECURITY CLASS } \\
\text { (THIS PAGE) }\end{array}$ & 22. Price \\
UNCL ASSIFIED & $\$ .75$ Domestic Postpa id \\
\hline
\end{tabular}





\section{NBS TECHNICAL PUBLICATIONS}

PERIODICALS

JOURNAL OF RESEARCH reports National Bureau of Standards research and development in physics, mathematics, and chemistry. Comprehensive scientific papers give complete details of the work, including laboratory data, experimental procedures, and theoretical and mathematical analyses. Illustrated with photographs, drawings, and charts. Includes listings of other NBS papers as issued.

Published in two sections, available separately:

\section{- Physics and Chemistry (Section A)}

Papers of interest primarily to scientists working in these fields. This section covers a broad range of physical and chemical research, with major emphasis on standards of physical measurement, fundamental constants, and properties of matter. Issued six times a year. Annual subscription: Domestic, $\$ 17.00$; Foreign, \$21.25.

\section{- Mathematical Sciences (Section B)}

Studies and compilations designed mainly for the mathematician and theoretical physicist. Topics in mathematical statistics, theory of experiment design, numerical analysis, theoretical physics and chemistry, logical design and programming of computers and computer systems. Short numerical tables. Issued quarterly. Annual subscription: Domestic, $\$ 9.00$; Foreign, $\$ 11.25$.

\section{TECHNICAL NEWS BULLETIN}

The best single source of information concerning the Bureau's measurement, research, developmental, cooperative, and publication activities, this monthly publication is designed for the industry-oriented individual whose daily work involves intimate contact with science and technology-for engineers, chemists, physicists, research managers, product-development managers, and company executives. Includes listing of all NBS papers as issued. Annual subscription: Domestic, $\$ 6.50$; Foreign, $\$ 8.25$.

\section{MOHPERIODICALS}

Applied Mathematics Series. Mathematical tables, manuals, and studies.

Building Science Series. Research results, test methods, and performance criteria of building materials, components, systems, and structures.

Handbooks. Recommended codes of engineering and industrial practice (including safety codes) developed in cooperation with interested industries, professional organizations, and regulatory bodies.

Special Publications. Proceedings of NBS conferences, bibliographies, annual reports, wall charts, pamphlets, etc.

Monographs. Major contributions to the technical literature on various subjects related to the Bureau's scientific and technical activities.

National Standard Reference Data Series. NSRDS provides quantitative data on the physical and chemical properties of materials, compiled from the world's literature and critically evaluated.

Product Standards. Provide requirements for sizes, types, quality, and methods for testing various industrial products. These standards are developed cooperatively with interested Government and industry groups and provide the basis for common understanding of product characteristics for both buyers and sellers. Their use is voluntary.

Technical Notes. This series consists of communications and reports covering both other-agency and NBS-sponsored work) of limited or transitory interest.

Federal Information Processing Standards Publications. This series is the official publication within the Federal Government for information on standards adopted and promulgated under the Public Law 89-306, and Bureau of the Budget Circular A-86 entitled, Standardization of Data Elements and Codes in Data Systems.

Consumer Information Series. Practical information, based on NBS research and experience, covering areas of interest to the consumer. Easily understandable language and illustrations provide useful background knowledge for shopping in today's technological marketplacc.

\section{BIBLIOGRAPHIC SUBSCRIPTION SERVICES}

The following current-awareness and literature-survey bibliographies are issued periodically by the Bureau:

Cryogenic Data Center Current Awareness Service (Publications and Reports of Interest in Cryogenics). A literature survey issued weekly. Annual subscription: Domestic, $\$ 20.00$; foreign, $\$ 25.00$.

Liquefied Natural Gas. A literature survey issued quarterly. Annual subscription: $\$ 20.00$.

Superconducting Devices and Materials. A literature survey issued quarterly. Annual subscription: $\$ 20.00$. Send subscription orders and remittances for the preceding bibliographic services to the U.S. Department of Commerce, National Technical Information Service, Springfield, Va. 22151.

Electromagnetic Metrology Current Awareness Service (Abstracts of Selected Articles on Measurement Techniques and Standards of Electromagnetic Quantities from D-C to Millimeter-Wave Frequencies). Issued monthly. Annual subscription: $\$ 100.00$ (Special rates for multi-subscriptions). Send subscription order and remittance to the Electromagnetic Metrology Information Center, Electromagnetics Division, National Bureau of Standards, Boulder, Colo. 80302.

Order NBS publications (except Bibliographic Subscription Services) from: Supcrintendent of Docunents, Government Printing Office, Washington, D.C. 20402. 
U.S. DEPARTMENT OF COMMERCE

National Bureau of Standards

Washington, D.C. 20234

DFFICIAL BUSINESS

Penalty for Private Use, \$3DD
PDSTAGE AND FEES PAID U.S. OEPARTMENT OF COMMERCE 215

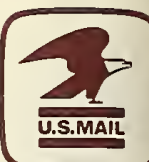

